\title{
Public knowledge about traditional and complementary medicine
}

\author{
Başak Bilir Kaya $\odot$, Melike Şahin $\odot$
}

Department of Physical Medicine and Rehabilitation, Erenköy Physical Therapy and Rehabilitation Hospital, Istanbul, Turkey

DOI: $10.18621 /$ eurj.429651

\begin{abstract}
Objectives: The aim of this study was to investigate public knowledge about traditional and complementary medicine.

Methods: In a physical medicine and rehabilitation hospital, questionnaires were administered to 534 volunteers. The questionnaires comprised of questions regarding demographic data such as age, gender and educational level and 16 additional questions about traditional and complementary medicine defitions. These definitions were directly adopted from Ministry of Health Department of Traditional and Complementery Medical Practices. The results were recorded and statistical analysis were carried out.

Results: The volunteers were $44.6 \%$ male and 55.4\% female). Acupuncture definition was known to $57.7 \%$ volunteers; this rate was $26.6 \%$ in phytotherapy, $32.2 \%$ in apitherapy, $43.4 \%$ in hypnosis, $15.2 \%$ in hirudotherapy, $28.7 \%$ in homeopathy, $11.9 \%$ in chiropractic, $32.2 \%$ in cupping therapy, $40.4 \%$ in wet cupping therapy, $29 \%$ in maggot therapy, $27.3 \%$ in mesotherapy, $18 \%$ in prolotherapy, $22.1 \%$ in osteopathy, $38.8 \%$ in ozone therapy, $40.6 \%$ in reflexology, $55.2 \%$ in music therapy. Women's correct answers regarding hypnosis, reflexology and music therapy were found to be statistically significantly higher than men. Acupuncture and osteopathy definitions are better known to 18-30 years old volunteers than volunteers that are older than 65 years of age. Apitherapy, homeopathy, cupping, wet cupping, maggot therapy, mesotherapy, prolotherapy, ozon therapy, reflexology were less known by the older population; as the age increased the correct answers for these therapies decreased. In addition, correct answer ratio increased with the educational level, in acupuncture, apitherapy, phytotherapy, hypnosis, chariopractic, cupping, wet cupping, mesotherapy, ozone therapy and reflexology.

Conclusions: The traditional and complementary therapies need to be explained to the public. Women are more intersted in some therapies than men. Public knowledge about the definition of most traditional and complementary therapies increases with educational level. People with different demographic properties have different levels of awareness regarding traditional and complementary therapies. For example while elder people require more basic training about these methods in general, young and highly educated women who already have some awareness about these methods can go through more elaborate training programs which are designed to guide them to benefit more from these therapies.
\end{abstract}

Keywords: health literacy, acupuncture, cupping therapy, complementary health approaches, osteopathy

Received: June 1, 2018; Accepted: November 2, 2018; Published Online: June 10, 2019

Address for correspondence: Başak Bilir Kaya, MD., İstanbul Erenköy Physical Therapy and Rehabilitation Hospital, Department Physical Medicine and Rehabilitation, İstanbul, Turkey

E-mail: basakbilir@gmail.com 
$\mathbf{P}$ eople, especially those with chronic diseases, sometimes seek treatment options other than modern medicine, such as complementary and traditional therapies. In 2011, General Directorate of Health Services at Ministry of Health established a spesific unit named as Department of Traditional and Complementery Medical Practices in Turkey. In 2014 regulation on traditional and complementary medical practices was published [1]. In this guide there were 16 traditional and complementary treatments. These treatments are: acupuncture [2], apitherapy [3], phytotherapy [4], hypnosis [5], hirudotherapy [6], homeopathy [7], chiropractic [8], cupping [9], wet cupping [9], maggot therapy [10], mesotherapy [11], prolotherapy [12], osteopathy [13], ozone therapy [14], reflexology [15], and musical therapy [16]. The definition of these therapies were given in the respected references cited above. The explanation of these theraphies, exactly as provided by the Ministry of Health of Turkey are given in the following: (1) Acupuncture: It is a treatment method in which, special points (selected from the ear or the whole body) are stimulated with special needles or laser-like stimulants; (2) Apitherapy: It is a complementary and preventive method, where bee and bee products are used; (3) Phytotherapy: A traditional and complementary method that benefits from herbs which are scientifically proven to have protective effects against diseases and to promote treatment; (4) Hypnosis: An artificially induced altered state of consciousness which is achieved by inculcation; (5) Hirudotherapy: A treatment method which uses leeches; (6) Homeopathy: A method which uses homeopathic medicine for holistic treatment; (7) Chiropractic: It is a supportive practice area dealing with biomechanical disorders of the muscles, spine and skeletal system and preventing the problems it creates on the nervous system. In appropiate patients it focuses onmanually fixing mobility of joints that have lost their mechanical movement; (8) Cupping: Traditional treatment method based on creating regional vacuum to increase blood circulation and improve healing; (9) Wet cupping: Dirty blood is taken from capillaries and thin veins at certain points where waste materials are collected intensively to get rid of disease or to protect health; (10) Maggot therapy: Application of, Lucilia (Phaenicia) Sericata, a sterile larvae for the purpose of biological cleansing in chronic wounds; (11) Mesotherapy: It is an injection method of herbal and pharmacological drugs for the healing of mesoderm originated organs; (12) Prolotherapy: It is a treatment method based on the principle that the proliferation-inducing and irritating solutions given to the muscles or joints increases flexibility of the skeletal system; (13) Osteopathy: It is a non-invasive (needle-free, non-surgical) complementary medicine technique that helps strengthen the musculoskeletal system, including joints, muscles, connective tissue and the vertebrae, focuses on whole body health and emphasizes the effectiveness of the musculoskeletal system in diseases; (14) Ozone therapy: Ozone is a traditional and complementary medical method that is applied by mixing the ozone gas obtained from pure oxygen with the patient's own blood or serum physiologic, or by giving it to various parts of the body in gas; (15) Reflexology: It is a treatment method which is based onthe principle that there are reflex areas on hand, feet and ears which are connected to the whole body; and (16) Musical therapy: It is a therapy and rehabilitation approach aimed at improving and acquiring the functions and skills that are corrupted, lost or underdeveloped for various reasons through music. The aim of this study is to evaluate the public knowledge about these traditional andcomplimentary medical approaches.

\section{METHODS}

Five hundred and thirty-four people at a government owned physical medicine and rehabilitation hospital were included in the study. The study is a cross-sectional and descriptive study, performed between April 1 $1^{\text {st }}, 2018$ and April 20 ${ }^{\text {th }}$, 2018. Volunteers were patients at the outpatient clinic, inpatient clinic, patient companions and relatives which accepted to fill the form.

Inclusion criteria are the following: (1) to be older then 18 years old and younger then 90 years old; (2) able to read or understand Turkish; (3) to volunteer to fill the test. Also exclusion criteria include not volunteer to fill the test or not understanding Turkish. Questionnairesabout the traditional and complimentary medicine definitions are distributed to the volunteers at the hospital. The definitions of traditional and complimentary medicine techniques were taken from Ministry of Health Department of 
Traditional and Complementery Medical Practices web site. Volunteers' age, gender, educational levels were collected via the same questionnaire. There were no personal information on the questionnaires, hence they were all anonymous. After the demographic characteristics of the volunteers were recorded, all traditional and complimentary medicine definitions are evaluated as correct, incorrector blank. We investigated if there is any statistically different relationship between volunteers' age, gender or educational level and the knowledge about the traditional and complimentary medicine.

\section{Statistical Analysis}

For the statistical analyses, the IBM SPSS statistic 22 program was used. When the study data were evaluated, descriptive statistical methods (mean, standard deviation, median, crosstabs) as well as paired sample $\mathrm{t}$ test were used for intra-group comparison of normal distribution parameters and Anova test was used for intra-group comparison of non-normal distribution parameters. The results were assessed at a 95\% confidence interval and at a significance level of $p<0.05$.

\section{RESULTS}

There were 534 participants including 296 (55.4\%) females and 238 (44.6\%) males. One hundred and eleven $(20.8 \%)$ volunteers were between $18-30$ years old, $116(21.7 \%)$ were $31-40$ years old, 109 (20.4\%) were $41-50$ years old, 114 were $51-65$ years old $(21.3 \%), 84(15.7 \%)$ were $66-90$ years old.
According to their education, participants were divided into six levels: (1) Unable to read and write: 39 (7.3\%); (2) Primary school: 110 (20.6\%); (3) Secondary school: 108 (20.2\%); (4) High school: 140 (26.2\%); (5) University: 122 (22.8\%) and (6) Postgraduate: $15(2.8 \%)$.

The highest number of correct answers about the definitions of traditional and complemantary medicine was in acupuncture (57.7\%) and lowest was in chiropractic $(11.0 \%)$. The other percentages of correct answers were as follows: music therapy $55.2 \%$, hypnosis $43.4 \%$, reflexology $40.6 \%$, wet cupping $40.4 \%$, ozontherapy $38.8 \%$, apitherapy $32.2 \%$, cupping $32.2 \%$, maggot therapy $29.0 \%$, homeopathy $28.7 \%$, mesotherapy $27.3 \%$ phytotherapy $26.6 \%$, osteopathy $22.1 \%$, prolotherapy $18.0 \%$, and hirudotherapy $15.2 \%$.

Whether there is a significant correlation between the gender of participants and their knowledge of traditional and complementary medical practices was evaluated with T-test and it was seen that the correct answers of women regarding hypnosis, reflexology and music therapy are higher than men (Table 1). Table 1 only includes data which resulted in statistically significant differences between men and women.

There is a significant difference between the age of the participants and their knowledge of traditional and complementary medical practices. Acupuncture $(p=0.13)$ and osteopathy $(p=0.30)$ definitions are better known to 18-30 years old participants than those 65 years and older. Apitherapy, homeopathy, cup therapy, wet cupping, maggot therapy, mesotherapy, prolotherapy, ozone therapy and reflexology correct

Table 1. Relationship between gender and knowledge about traditional and complimentary medicine

\begin{tabular}{lcccc}
\hline $\mathbf{n}=\mathbf{5 3 4}$ & True & False & No Answer & $\boldsymbol{p}$ value \\
\hline Hypnosis & & & & $\mathbf{0 . 0 1 8}$ \\
Female $(\mathrm{n}=296)$ & $142(61)$ & $110(52 \%)$ & $44(48 \%)$ & \\
Male $(\mathrm{n}=238)$ & $90(39 \%)$ & $101(48 \%)$ & $47(52 \%)$ & \\
Reflexology & & & & $\mathbf{0 . 0 1 4}$ \\
Female $(\mathrm{n}=296)$ & $137(63 \%)$ & $97(49.5 \%)$ & $62(51 \%)$ & \\
Male ( $=238)$ & $80(37 \%)$ & $99(50.5 \%)$ & $59(49 \%)$ & \\
Music therapy & & & & \\
Female $(\mathrm{n}=296)$ & $179(60.6 \%)$ & $78(47 \%)$ & $39(52.7 \%)$ & \\
Male $(\mathrm{n}=238)$ & $116(39.4 \%)$ & $87(53 \%)$ & $35(47.3)$ & \\
\hline
\end{tabular}


answers seem to decrease as the age increases (Table knowledge about traditional and complimentary 2).

Relationship between level of education and medicine is shown in Table 3.

Table 2. Relationship between age and knowledge about traditional and complimentary medicine

\begin{tabular}{|c|c|c|c|c|c|}
\hline $\mathrm{n}=\mathbf{5 3 4}$ & $\begin{array}{c}18-30 \text { years } \\
n=111\end{array}$ & $\begin{array}{c}31-40 \text { years } \\
n=116\end{array}$ & $\begin{array}{c}41-50 \text { years } \\
\mathrm{n}=109\end{array}$ & $\begin{array}{c}51-65 \text { years } \\
n=114\end{array}$ & $\begin{array}{c}>65 \text { years } \\
n=84\end{array}$ \\
\hline \multicolumn{6}{|l|}{ Apitherapy } \\
\hline True & $52(46.8 \%)$ & $42(36.2 \%)$ & $29(26.6 \%)$ & $33(28.9 \%)$ & $16(19 \%)$ \\
\hline False & $47(42.4 \%)$ & $53(45.7 \%)$ & $58(53.2 \%)$ & $60(52.6 \%)$ & $33(39.3 \%)$ \\
\hline Blank & $12(10.8 \%)$ & $21(18.1 \%)$ & $22(20.2 \%)$ & $21(18.4 \%)$ & $35(41.7 \%)$ \\
\hline \multicolumn{6}{|l|}{ Homeopathy } \\
\hline True & $45(40.5 \%)$ & $32(27.6 \%)$ & $28(25.7 \%)$ & $28(24.6 \%)$ & $20(23.8 \%)$ \\
\hline False & $52(46.8 \%)$ & $56(48.3 \%)$ & $55(50.5 \%)$ & $51(44.7 \%)$ & $30(35.7 \%)$ \\
\hline Blank & $14(12.6 \%)$ & $28(24.1 \%)$ & $26(23.8 \%)$ & $35(30.7 \%)$ & $34(40.5 \%)$ \\
\hline \multicolumn{6}{|l|}{ Cupping } \\
\hline True & $47(42.4 \%)$ & $43(37.1 \%)$ & $28(25.7 \%)$ & $32(28.1 \%)$ & $22(26.2 \%)$ \\
\hline False & $52(46.8 \%)$ & $56(48.3 \%)$ & $55(50.5 \%)$ & $63(55.3 \%)$ & $39(46.4 \%)$ \\
\hline Blank & $12(10.8 \%)$ & $17(14.6 \%)$ & $26(23.8 \%)$ & $19(16.6 \%)$ & $23(27.4 \%)$ \\
\hline \multicolumn{6}{|l|}{ Wet Cupping } \\
\hline True & $55(49.5 \%)$ & $50(43.1 \%)$ & $38(34.9 \%)$ & $42(36.9 \%)$ & $31(36.9 \%)$ \\
\hline False & $48(43.3 \%)$ & $46(31.7 \%)$ & $51(46.8 \%)$ & $47(41.2 \%)$ & $25(29.8 \%)$ \\
\hline Blank & $8(7.2 \%)$ & $20(17.2 \%)$ & $20(18.3 \%)$ & $25(21.9 \%)$ & $28(33.3 \%)$ \\
\hline \multicolumn{6}{|c|}{ Maggot therapy } \\
\hline True & $43(38.7 \%)$ & $36(31 \%)$ & $24(22 \%)$ & $33(28.9 \%)$ & $19(22.6 \%)$ \\
\hline False & $49(44.1 \%)$ & $48(41.4 \%)$ & $55(50.5 \%)$ & $50(43.9 \%)$ & $29(34.5 \%)$ \\
\hline Blank & $19(17.2 \%)$ & $32(27.6 \%)$ & $30(27.5 \%)$ & $31(27.2 \%)$ & $36(42.9 \%)$ \\
\hline \multicolumn{6}{|l|}{ Mesotherapy } \\
\hline True & $39(35.1 \%)$ & $33(28.4 \%)$ & $29(26.6 \%)$ & $27(23.7 \%)$ & $18(21.4 \%)$ \\
\hline False & $55(49.5 \%)$ & $54(46.6 \%)$ & $44(40.4 \%)$ & $59(51.7 \%)$ & $33(39.3 \%)$ \\
\hline Blank & $17(15.3 \%)$ & $29(25 \%)$ & $36(33 \%)$ & $28(24.6 \%)$ & $33(39.3 \%)$ \\
\hline \multicolumn{6}{|l|}{ Prolotherapy } \\
\hline True & $27(24.3 \%)$ & $24(20.7 \%)$ & $17(15.6 \%)$ & $18(15.8 \%)$ & $10(11.9 \%)$ \\
\hline False & $64(57.7 \%)$ & $56(48.3 \%)$ & $62(56.9 \%)$ & $62(54.4 \%)$ & $38(45.2 \%)$ \\
\hline Blank & $12(10.8 \%)$ & $36(31 \%)$ & $30(27.5 \%)$ & $34(29.8 \%)$ & $36(42.9 \%)$ \\
\hline \multicolumn{6}{|c|}{ Ozone Therapy } \\
\hline True & $52(46.9 \%)$ & $50(43.1 \%)$ & $42(38.5 \%)$ & $41(36 \%)$ & $22(26.2 \%)$ \\
\hline False & $44(39.6 \%)$ & 37 (31.9\%) & $37(34 \%)$ & $40(35.1 \%)$ & $31(36.9 \%)$ \\
\hline Blank & $15(13.5)$ & $29(25 \%)$ & $30(27.5 \%)$ & $33(28.9 \%)$ & $31(36.9)$ \\
\hline \multicolumn{6}{|l|}{ Reflexology } \\
\hline True & $57(51.4 \%)$ & $43(37.1 \%)$ & $49(45 \%)$ & $44(38.6 \%)$ & $24(28.6 \%)$ \\
\hline False & $42(37.8 \%)$ & $47(40.5 \%)$ & $36(33 \%)$ & $42(36.8 \%)$ & $29(34.5 \%)$ \\
\hline Blank & $12(10.8 \%)$ & $26(22.4 \%)$ & $24(22 \%)$ & $28(24.6 \%)$ & $31(36.9 \%)$ \\
\hline
\end{tabular}


Table 3. Relationship between level of education and knowledge about traditional and complimentary medicine

\begin{tabular}{ccccccc}
\hline $\mathbf{n = 5 3 4}$ & $\begin{array}{c}\text { Postgraduate } \\
\mathbf{n = 1 5}\end{array}$ & $\begin{array}{c}\text { University } \\
\mathbf{n = 1 2 2}\end{array}$ & $\begin{array}{c}\text { High } \\
\text { School } \\
\mathbf{n = 1 4 0}\end{array}$ & $\begin{array}{c}\text { Secondary } \\
\text { School } \\
\mathbf{n = 1 0 8}\end{array}$ & $\begin{array}{c}\text { Primary } \\
\text { School } \\
\mathbf{n = 1 1 0}\end{array}$ & $\begin{array}{c}\text { Non-reader } \\
\text { or writer } \\
\mathbf{n}=\mathbf{3 9}\end{array}$ \\
\hline $\begin{array}{c}\text { Reflexology } \\
\text { True }\end{array}$ & $11(73.3 \%)$ & $73(59.8 \%)$ & $66(41.1 \%)$ & $39(36.1 \%)$ & $23(20.9 \%)$ & $5(12.8 \%)$ \\
False & $3(20 \%)$ & $35(28.7 \%)$ & $46(32.9 \%)$ & $47(43.5 \%)$ & $49(44.5 \%)$ & $16(41 \%)$ \\
Blank & $1(6.7 \%)$ & $14(11.5 \%)$ & $28(20 \%)$ & $22(22.4 \%)$ & $38(34.5 \%)$ & $18(46.2 \%)$ \\
Acupuncture & & & & & & \\
True & $13(86.7 \%)$ & $100(82 \%)$ & $90(64.3 \%)$ & $43(39.8 \%)$ & $50(45.5 \%)$ & $12(30.8 \%)$ \\
False & $2(13.3 \%)$ & $17(13.9 \%)$ & $41(29.3 \%)$ & $58(53.7 \%)$ & $50(45.5 \%)$ & $16(41 \%)$ \\
Blank & 0 & $5(4.1 \%)$ & $9(6.4 \%)$ & $7(6.5 \%)$ & $10(9.1 \%)$ & $11(28.2 \%)$ \\
Apitherapy & & & & & & \\
True & $9(60 \%)$ & $68(55.7 \%)$ & $43(30.7 \%)$ & $22(20.4 \%)$ & $27(24.5 \%)$ & $3(7.7 \%)$ \\
False & $5(33.3 \%)$ & $39(32 \%)$ & $65(46.4 \%)$ & $70(64.8 \%)$ & $54(49.1 \%)$ & $18(46.2 \%)$ \\
Blank & $1(6.7 \%)$ & $15(12.3 \%)$ & $32(22.9 \%)$ & $16(14.8 \%)$ & $29(26.4 \%)$ & $18(46.2 \%)$ \\
Cupping & & & & & & \\
True & $9(60 \%)$ & $65(53.3 \%)$ & $45(32.1 \%)$ & $23(21.3 \%)$ & $26(23.6 \%)$ & $4(10.3 \%)$ \\
False & $6(40 \%)$ & $47(38.5 \%)$ & $69(49.3 \%)$ & $67(62 \%)$ & $57(51.8 \%)$ & $19(48.7 \%)$ \\
Blank & 0 & $10(8.2 \%)$ & $26(18.6 \%)$ & $18(16.7 \%)$ & $27(24.5 \%)$ & $16(41 \%)$ \\
Wet Cupping & & & & & & \\
True & $10(66.7 \%)$ & $81(66.4 \%)$ & $57(40.7 \%)$ & $23(21.3 \%)$ & $35(31.8 \%)$ & $10(25.6 \%)$ \\
False & $4(26.7 \%)$ & $32(26.2 \%)$ & $62(44.3 \%)$ & $62(57.4 \%)$ & $47(42.7 \%)$ & $10(25.6 \%)$ \\
Blank & $1(6.7 \%)$ & $9(7.4 \%)$ & $21(15 \%)$ & $23(21.3 \%)$ & $28(25.5 \%)$ & $19(48.7 \%)$ \\
Mesotherapy & & & & & & \\
True & $11(73.3 \%)$ & $49(40.2 \%)$ & $40(28.6 \%)$ & $19(17.6 \%)$ & $21(19.1 \%)$ & $6(15.4 \%)$ \\
False & $3(20 \%)$ & $53(43.4 \%)$ & $64(45.7 \%)$ & $62(57.4 \%)$ & $49(44.5 \%)$ & $14(35.9 \%)$ \\
Blank & $1(6.7 \%)$ & $20(16.4 \%)$ & $36(25.7 \%)$ & $27(25 \%)$ & $40(36.4 \%)$ & $19(48.7 \%)$ \\
True & $11(73.3 \%)$ & $75(61.5 \%)$ & $51(36.4 \%)$ & $31(28.7 \%)$ & $33(30 \%)$ & $6(15.4 \%)$ \\
False & $4(26.7 \%)$ & $32(26.2 \%)$ & $51(36.4 \%)$ & $46(42.6 \%)$ & $43(39.1 \%)$ & $13(33.3 \%)$ \\
Blank & 0 & $15(12.3 \%)$ & $38(27.1 \%)$ & $31(28.7 \%)$ & $34(30.9 \%)$ & $20(51.3 \%)$ \\
\hline Ozone $)$ & & & & &
\end{tabular}

\section{DISCUSSION}

In recent years, the estimated life span and incidence of chronic diseases have increased. As a result people began to seek for alternative therapies which will be used in conjunction with modern medicine $[17,18]$. To establish a legal basis on application of complamentary and alternative medicine in our country; in 2011, General Directorate of Health Services at Ministry of Health appointed a spesific unit called Department of Traditional and Complementery Medical Practices. In 2014 the regulation for traditional and complementary medical practices was published [1].

This step taken by the state is very important because this issue is very vulnerable to abuse. With this regulation, education curriculum of traditional and complementary treatments was determined and standardized. Institutions that can provide education were specified and those without proper certification 
have been prevented from applying traditional and complementary medicine [19].

In a study conducted in 8 countries across Europe on health literacy, it was observed that the level of education was high in groups with high health literacy scores [20]. This data is compatible with our study. As a matter of fact, it seems that the number of correct answers of high school, university and post-graduate education levels in acupuncture, apitherapy, cupping, wet cupping, mesotherapy, ozone therapy and osteopathy questions increases as education level increases. The number of correct answers given by people who are unable to read and write, primary school graduates and junior high school graduates are less than those of high school and post-education groups. Another consequence of the study done in Europe is that as age increases, health literacy decreases [20]. In our study, it is observed that the number of correct answers decreases as the age of the volunteers increases for apitherapy, homeopathy, cupping, wet cupping, maggot therapy, mesotherapy, prolotherapy, ozone and reflexology questions. Although these treatments have been used traditionally, they are less known by the older population and this may have been caused by the expected reduction in health literacy scores with age.

Another statistically significant finding in our study is that women have given higher number of correct answers in reflexology, hypnosis, and music therapy. This data is also compatible with traditional and complementary studies. Gözüm et al. [21] have reported that in a study conducted in 107 cancer patients, women were significantly more likely to use complementary health approaches. Akyol et al. [22] also found that women use more complementary and alternative therapies than man. In 207 chronic kidney disease patients only $5.8 \%$ of the patients used these alternative and complementary therapies with doctor advice. Also, it is reported that $67.3 \%$ of the patients who resort to alternative and complementary methods do not report their involvement in such therapies to their doctors [22].

Traditional and complementary medical practices should be planned and implemented in accordance with the regulation, by competent health professionals. In order to increase health literacy in a wider range of patients proper training programs should be established.

\section{CONCLUSION}

As suggested by the literature survey and our own findings, people with different demographic properties have different level of awareness regarding traditional and complementary therapies. While elder people require more basic training about these methods in general, young and highly educated women who already have some awareness about these methods can go through more elaborate training programs which are designed to guide them to benefit more from these therapies.

\section{Authors Contribution}

$\mathrm{BBK}=$ study planning, consultant, last reading, corrections and article writing; MŞ = data collection, statistics.

\section{Conflict of interest}

The author disclosed no conflict of interest during the preparation or publication of this manuscript.

\section{Financing}

The author disclosed that they did not receive any grant during conduction or writing of this study.

\section{REFERENCES}

[1] Turkey - Official Gazette. Number: 29187, Law No: 6569, 2014.

[2] Bivins R. The needle and the lancet: acupuncture in Britain, 1683-2000. Acupunct Med 2001;19:2-14.

[3] Mulholland S, Chang AB. Honey and lozenges for children with nonspecific cough. Cochrane Database Syst Rev 2009;(2):CD007523.

[4] Eisenberg DM, Davis RB, Ettner SL, Appel S, Wilkey S, Van Rompay M, et al. Trends in alternative medicine use in the United States, 1990-1997: results of a follow-up national survey. JAMA 1998;280:1569-75.

[5] Izquierdo de Santiago A, Khan M. Hypnosis for schizophrenia. Cochrane Database Syst Rev 2007;(4):CD004160. [6] Baskova IP, Kostrjukova ES, Vlasova MA. Proteins and peptides of the salivary gland secretion of medicinal leeches Hirudo verbana, H. medicinalis, and H. orientalis. Biochemistry Mosc 2008;73:315-20.

[7] Sankaran P. Some hints on case taking In: Sankaran R, editor., ed. The Elements of Homeopathy. Mumbai, India: Homeopathic Medical Publishers; 1996:207-17.

[8] Jamison JR, McEwen AP, Thomas SJ. Chiropractic adjustment in the management of visceral conditions: a critical appraisal. J Manipulative Physiol Ther 1992;15:171-80. 
[9] Chirali IZ. Cupping therapy. In: Chirali, editor. Traditional Chinese Medicine E-Book. Churchill Livinstone, Elsevier: Philadelphia, 2007.

[10] Pechter EA, Sherman RA. Maggot therapy: the surgical metamorphosis. Plast Reconstr Surg 1983;72:567-70.

[11] Mammucari M, Gatti A, Maggiori S, Sabato AF. Role of mesotherapy in musculoskeletal pain: opinions from the Italian society of mesotherapy. Evid Based Complement Alternat Med 2012;2012:436959.

[12] Reeves KD, Hassanein K. Randomized prospective doubleblind placebo-controlled study of dextrose prolotherapy for knee osteoarthritis with or without ACL laxity. Altern Ther Health Med 2000;6:68-80.

[13] Still AT. Autobiography of Andrew T. Still, with a history of the discovery and development of the science of osteopathy, together with an account of the founding of the American school of osteopathy. $1897 . \quad$ Available: http://archive.org/details/autobiographyand00stiliala

[14] Bocci V. Biological and clinical effects of ozone. Has ozone therapy a future in medicine. Br J Biomed Sci 1999;56:270-9.

[15] Kunz K., Kunz B. Understanding the science and art of reflexology. Altern Complement Ther 1995;1:183-6.
[16] American Music Theraphy Association Definition of Music Therapy 2018 Available online: https://www.musictherapy.org/about/musictherapy/

[17] The Lancet NCD Action Group and NDC Alliance. Priority actions for the non-communicabla disease crisis. Lancet 2011;377:1438-47.

[18] Tindle HA, Davis RB, Phillips RS, Eisenberg DM. Trends in use of complementary and alternative medicine by US adults: 1997-2002. Altern Ther Health Med 2005;11:42-9.

[19] Nutbeam D. Health promotion glossary. Health Promot Int 1998; 13:349-64.

[20] Sørensen K, Pelikan JM, Röthlin F, Ganahl K, Slonska Z, Doyle G, et al; HLS-EU Consortium. Health literacy in Europe: comparative results of the European health literacy survey (HLSEU). Eur J Public Health 2015;25:1053-8.

[21] Gözüm S, Tezel A, Koc M. Complementary alternative treatments used by patients with cancer in eastern Turkey. Cancer Nurs 2003;26:230-6.

[22] Akyol AD, Yildirim Y, Toker E, Yavuz B. The use of complementary and alternative medicine among chronic renal failure patients. J Clin Nurs 2011;20:1035-43. 